\title{
ANALISIS LAJU KOROSI BAJA ST 60 PASCA PROSES LAS GTA $W$ DENGAN VARIASI ARUS LAS 80, 100, 120 A DAN DIRENDAM PADA LARUTAN HCL BERSUHU 40 CELCIUS
}

\author{
Gabriyel Aditya Yudi*, Sri Mulyo Bondan Respati dan Imam Syafa'at \\ Jurusan Teknik Mesin, Fakultas Teknik, Universitas Wahid Hasyim \\ Jl. Menoreh Tengah X/22, Sampangan, Semarang 50236. \\ "Email: gabriye194@gmail.com
}

\begin{abstract}
Abstrak
Korosi merupakan suatu proses dimana proses ini menimbulkan suatu masalah karena dapat menghambat sebuah pekerjaan. Dalam hal ini korosi juga dapat menyerang besi baja ST60, baja yang dalam kehidupan sehari hari sangat mudah untuk diaplikasikan. Salah satu pengaplikasiannya adalah pembuatan pipa. Pipa digunakan sebagai sarana transportasi pengalir cairan, karena dianggap lebih murah dan effisien, slah satunya aliran $\mathrm{HCl}$. Untuk mendapat panjang pipa yang diinginkan dapat digunakan proses pengelasan sebagai penyambung. Dalam tulisan ini dilakukan pengujian laju korosi serta pengaruh korosi terhadapt baja ST60 dengan variasi arus las 80, 100, 120 A dan tanpa proses pengelasan yang direndam dalam larutan $\mathrm{HCl}$ selama 72 jam. Hasilnya Dengan hasil selisih rata rata tanpa pengelasan 17,07 gram dan dengan lasan 120A didapat 15,48 gram.Serta laju korosi tertinggi pada proses tanpa pengelasan yaitu 13,6.10 $0^{2} \mathrm{MPY}$, setelah itu turun 1,4\% yaitu di pengelasan $80 \mathrm{~A}$ dengan hasil $13,43.10^{2} \mathrm{MPY}$, kemudian turun kembali 4,8\% menjadi $12,8.10^{2} \mathrm{MPY}$ dan terakhir laju korosi terendah dengan pengelasan 120A, turun 9,3\% menjadi 12,35.10 MPY. Serta uji kekerasan 80A yang semula 61,3 naik menjadi 61,53 dengan menggunakan metode HRB. Hal tersebebut terjadi di semua spesimen termasuk 100A, 120A dan tanpa proses pengelasan. Dapat diketahui semakin tinggi amper semakin tinggi kekerasan karena semakin tinggi temperaturnya, dan berbanding terbalik dengan laju korosinya yang semakin rendah.
\end{abstract}

Kata kunci: korosi, laju korosi, baja st60, GTAW

\section{PENDAHULUAN}

Korosi merupakan hal yang paling sering dijumpai dalam kehidupan sehari hari. Korosi merupakan fenomena alamiah yang dapat terjadi pada kebanyakan unsur yang mengandung logam, dimana korosi merupakan suatu proses kerusakan material karena reaksi kimia atau elektro kimia dengan lingkungannya. Seluruh bahan yang mengandung unsur logam dapat rusak karena korosi (Trethewey dan Chamberlain, 1991).

Baja ST 60 merupakan salah satu baja yang mudah terserang korosi, baja yang salah satunya di gunakan sebagai bahan baku pembuat pipa ini tergolong baja karbon sedang dalam standart DIN 17100. Baja karbon sedang merupakan baja dengan kekuatan tarik antara 25 sampai60kg/mm2. Baja ST 60 juga dapat digunakan atau dapat diaplikasikan dengan mudah untuk kegiatan manufaktur. Contohnya adalah pengelasan.
Pengelasan adalah salah salah satu teknik penyambungan logam dengan cara mencairkan sebagian logam induk dan logam pengisi dengan atau tanpa tekanan dan dengan atau tanpa logam penambah dan menghasilkan sambungan yang kontinyu. Salah satu jenis pengelasan adalah las GTAW (Gas Tungsten Arc Welding). Pengelasan ini dikenal rapih dan memiliki hasil yang lebih sempurna dibanding dengan jenis pengelasan lainnya. Pada pengelasan GTAW ini elektroda atau tungsten ini hanya berfungsi sebagai penghasil busur listrik saat bersentuhan dengan benda kerja, sedangkan untuk logam pengisi adalah filler rod. Pengelasan GTAW ini juga sering disebut dengan Las Argon, hal tersebut dikarenakan gas pelindung yang digunakan adalah gas Argon. Untuk mengoprasikan Las Argon ini dapat disesuaikan besar Arus yang diperlukan. Besar Arus di perlukan untuk menentukan arus yang tepat untuk pengelasan, sehingga di dapat hasil yang maksimal. 
Salah satu contoh proses pengelasan dalam kehidupan sehari hari adalah penyambungan pipa untuk keperluan industri. Salah satu contoh penggunaan atau fungsi pipa dalam kehidupan sehari hari adalah sebagai media penyalur bahan gas maupun cair. Tak menutup kemungkinan bahan tersebut bersifat asam, contohnya $\mathrm{HCl}$. Pipa pipa yang terus menerus terkena larutan $\mathrm{HCl}$ maka akan terbentuk gumpalan (cluster), lubang (hole) dan retakan (crack) yang semakin banyak. Dari hasil uji SEM, bahan baja yang terkena larutan $\mathrm{HCl}$ terus menerus akan semakin cepat laju korosinya (Septianingsih dkk, 2014).

Proses pengelasan menyebabkan perubahan suhu yang tidak merata pada pipasaat proses pengelasan berlangsung, serta bersentuhan dengan larutan $\mathrm{HCl}$ secara terus menerus yang merupakan fungsi pipa sebagai media penyalur sehingga menyebabkan laju korosi pada pipa meningkat. Laju korosi sendiri merupakan kecepatan rambatan atau kecepatan penurunan kualitas bahan terhadap waktu (Fontana, 1987).

Penelitian ini dilakukan untuk mengetahui besar laju korosi pasca pengelasan GTAW yang di rendam dengan larutan $\mathrm{HCl}$. Dengan menggunakan variasi arus diharap dapat mengetahui arus mana yang tepat agar dapat mengurangi laju korsi. PD Putra dkk (2016) menganalisa perbandingan laju korosi lingkungan laut dari hasil pengelasan GMAW pada sambungan alumunium seri 5050 karena pengaruh variasi kecepatan aliran gas pelindung di dapat nya hasil semakin deras atau semakin kencang kecepatan aliran gas/menit akan mempengaruhi nilai kekerasan dan semakin keras suatu material semakin rendah pula laju korosinya.

Material alumunium seri 5050 didapat hasil yaitu dengan gas pelindung berkecepatan 15liter/menit menghasilkan kekerasan rata rata tertinggi $60.43 \mathrm{HVN}$ dan memiliki laju korosi $0.158 \mathrm{mmpy}$, kecepatan aliran gas 20liter/menit menghasilkan kekerasan tertinggi $62.8 \mathrm{HVN}$ dan memiliki laju korosi $0,1187 \mathrm{mmpy}$ serta kecepatan aliran gas 25liter/menit menghasilkan kekerasan tertinggi $67.33 \mathrm{HVN}$ dan laju korosi 0,0823mmpy.

Handoko dkk (2012) menganalisa perbandingan laju korosi pada baja karbon rendah St 40 dengan baja karbon sedang St 60 pada larutan air garam dengan dimensi bahan percobaan diamater dalam 0,5 inchi $(1,27 \mathrm{~cm})$ ketebalan 0,17 inchi $(0,45 \mathrm{~cm})$ dan panjang 0,78 inchi $(2 \mathrm{~cm})$. Pengujian dilakukan dalam waktu 100 jam dengan menggunakan masing masing 5 spesiment sebagai hasil pembanding. Didapatlah hasil laju korosi pada material baja ST 40 dan ST 60 adalah sebesar 7,76 mpy dan 4,44 mpy. Dengan hasil tersebut ED Handoko dkk menyimpulkan, bahwa baja ST 60 memiliki ketahanan laju korosi yang lebih bagus dari baja ST 40.

Yogi (2016) menganalisa pengaruh variasi arus las SMAW terhadap kekerasan dan kekuatan tarik sambungan didimilar stainless steel 304 dan st37. Pada proses ini arus las yang digunakan adalah 60A, 70A, dan 80A. Berdasarkan hasil pengujian dan ana-lisis data dapat disimpulkan bahwa variasi arus las SMAW pada sambungan stainless steel 304 dan ST 37 memberikan pengaruh pada kekerasannya. Semakin besar arus yang digunakan maka akan meningkatkan kekerasannya pada daerah weld metal dan nilai kekerasan terbesar dimiliki spesimen arus 80 ampere sebesar 92,5 HRB di titik 0 dan 93 HRB di titik 1.

Pada daerah batas weld metal, fusion line, dan HAZ kekerasan semakin besar arus maka akan tinggi kro-mium karbida dan meningkatkan kekerasan-nya dengan kekerasan terbesar pada spesi-men arus 60 ampere sebesar $91 \mathrm{HRB}$ di batas HAZ dan fusion line ST 37 dan 95 HRB di batas HAZ dan fusion line stainless steel 304, dan penurunan kekerasan di 80 ampere daerah batas HAZ dan fusion line karena difusi karbon dan kromium dengan nilai kekerasan 82 HRB.

Septianingsih dkk (2014) menganalisa pengaruh variasi konsentrasi Asam Klorida terhadap laju korosi baja karbon rendah Astm A 139 tanpa dan dengan inhibitor Kalium Kromat $0,2 \%$. Pada penelitian ini menggunakan $\mathrm{HCl}$ dengan kandungan masing masing 5\%, 10\%, dan $15 \% . \mathrm{HCl}$ sendiri merupakan larutan asam kuat.

Dari hasil percobaan yang telah dilakukan Septianingsih dkk, menunjukan hasil laju korosi yang terus naik sebanding dengan meningkatnya konsentrasi larutan $\mathrm{HCl}$ yang digunakan, dengan inhibitor maupun tanpa inhibitor. Hasil tersebut sesuai dengan teori laju korosi yang salah satu penyebab meningkatnya laju korosi adalah kandungan asam.

Tujuan penelitian ini adalah :Mengetahui pengaruh arus las GTAW terhadap Kekerasan sebelum dan pasca proses korosi. Mengetahui pengaruh arus las GTAW terhadap laju korosi 
yang direndam dalam larutan HCL bersuhu $40^{\circ} \mathrm{C}$.

\section{METODE PENELITIAN}

Metode penelitian ini menggunakan metode eksperimental.

Adapun Urutan penelitian dapat dilihat pada Gambar 1.

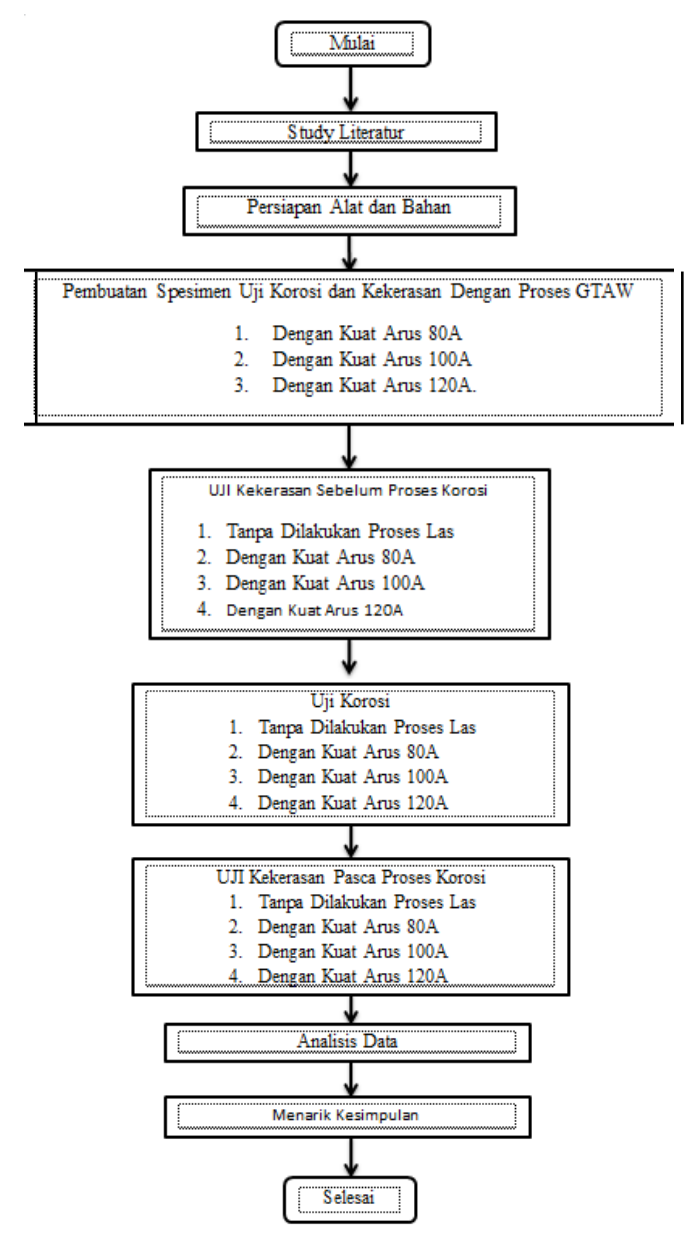

Gambar 1. Diagram Penelitian

Variabel bebas adalah variabel yang dapat mempengaruhi terjadinya suatu gejala di dalam suatu penelitian. Dalam penelitian ini yang menjadi variabel bebas adalah variasi besar arus dalam pengelasan GTAW yaitu 80A, 100A, dan 100A.

Variabel terikat adalah variabel yang dipengaruhi oleh variabel bebas. Variabel terikat dalam penelitian ini adalah baja ST60.

Variabel kontrol adalah faktor-faktor yang mempengaruhi hasil dari penelitian. Variabel kontrol dalam penelitian ini adalah jumlah campuran larutan $\mathrm{HCl}$ dengan Aquades, ketebalan spesimen korosi.
Bahan yang digunakan : Baja karbon sedang, Asam Klorida ( $\mathrm{HCl})$, Filler, Aquades

Alat yang digunakan : Mesin las Argon, Gerinda, Timbangan Digital, Mesin Uji Korosi

Langkah pembuatan mesin uji korosi sebgai berikut :Siapkan potongan plat akrilik berukuran $500 \mathrm{~mm} \times 500 \mathrm{~mm}$ sebanyak 2 buah, siapkan potongan plat akrilik berukuran $500 \mathrm{~mm}$ x $300 \mathrm{~mm}$ sebanyak 3 buah, sambung potongan potongan akrilik dengan menggunakan lem seperti gambar, siapkan gelas kaca sebanyak 1 buah, masukkan gelas kaca kedalam box yang telah dibuat, siapkan alat heater dan termostat, masukan termostat ke dalam gelas beserta heater, tuangkan larutan $\mathrm{HCl}$ kedalam gelas

Berikut langkah langkahnya Pembuatan Spesimen Uji Korosi, siapkan bahan plat baja st 60 dengan panjang $55 \mathrm{~mm}$, lebar $50 \mathrm{~mm}$ serta tebal $10 \mathrm{~mm}$ sebanyak 9 buah. Potong masing masing spesimen menjadi dua sehingga panjang menjadi $25 \mathrm{~mm}$, lebar tetap $55 \mathrm{~mm}$. Gerinda halus masing masing spesimen agar terlihat mengkilap dan bersihkan dari sisa sisa penggerindaan. Bersihkan spesiment dari minyak atau kotoran yang menempel menggunakan lap atau majun. Sambung kembali potongan tadi dengan menggunakan las GTAW, 3 buah dengan kuat arus 80A, 3 buah dengan kuat arus 100A, dan 3 buah dengan kuat arus 120A. Beri stamping pada masing masing spesiment untuk memisahkan proses pengelasan $80 \mathrm{~A}, 100 \mathrm{~A}, 120 \mathrm{~A}$ maupun tidak di las.

Langkah langkah pengujian korosi pada spesiment ini adalah sebagai berikut : Siapkan bahan pengujian korosi yang telah dibuat. Timbang mula mula berat setiap spesiment. Catat berat setiap spesiment dalam kolom atau kertas yang telah disediakan. Siapkan alat uji korosi dan jalankan heater agar suhu $\mathrm{HCl} 40^{\circ} \mathrm{C}$. Masukan ke-3 spesiment korosi dengan proses welding $80 \mathrm{~A}$ ke dalam alat uji korosi. Tunggu selama 72 jam. Timbang ke 3 spesimen, dan catat berat setelah dilakukan uji korosi. Lakukan hal yang sama pada spesimen hasil welding 100A, dan 120A, maupun tanpa welding.

Langkah langkah pengujian kekerasan pada spesiment ini adalah sebagai berikut : Siapkan bahan yang telah di las maupun yang tidak di las. Uji spesimen dengan alat uji kekerasan menggunakan metode HRB. Ikuti langkah pengroprasian yang sudah tertara di mesin. Catat hasil yang keluar, lakukan 6 kali 
percobaan pada masing- masing spesiment. Rata-rata lah hasil yang keluar, sehingga setiap spesimen memiliki satu hasil uji kekerasan. Lakukan proses diatas pada spesimen tanpa lasan, dengan las-an arus 80A, 100A, 120A.Tunggu spesimen mendapatkan proses pengujian korosi. Lakukan proses pengujian kekerasan seperti diatas setelah spesimen selesai uji korosi.

\section{HASIL DAN PEMBAHASAN \\ Hasil Pengelasan}

Pengelasan ini dilakukan untuk mendapatkan jenis perlakuan yang sama, yang digunakan dalam kehidupan nyata, dimana untuk menyambung dua buah pipa untuk mendapatkan panjang yang diinginkan. Pengelasan dilakukan dengan menggunakan metode GMAW, dan digunakan beberapa variabel perbedaan amper dalam pengelasan ini. Hasil dari pada pengelasan dapat dilihat dalam Gambar 2 sampai Gambar 4.

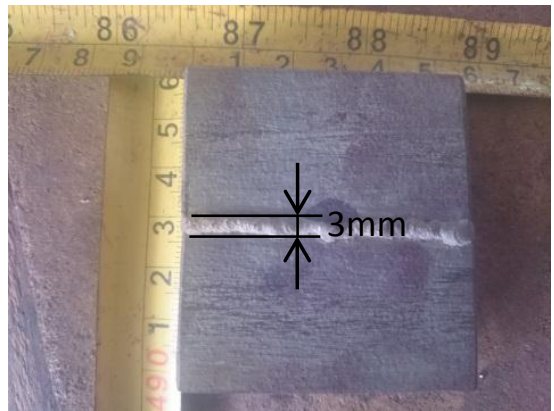

\section{Gambar 2. Foto Hasil Pengelasan 80A.}

Dari Gambar 2 merupakan hasil dari pengelasan GMAW menggunakan arus 80A. Pengelasan yang dilakukan mendapatkan lebar pengelasan $3 \mathrm{~mm}$.

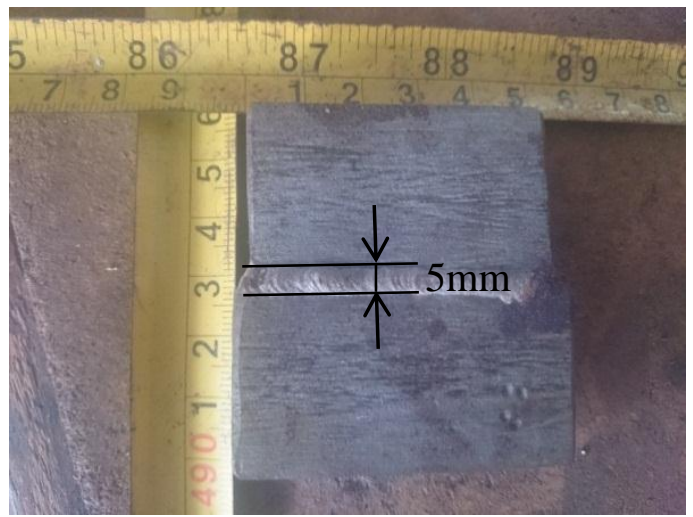

Gambar 3. Foto Hasil Pengelasan 100A.

Dari Gambar 3 merupakan hasil dari pengelasan GMAW menggunakan arus 100A.
Pengelasan yang dilakukan mendapatkan lebar pengelasan $5 \mathrm{~mm}$.

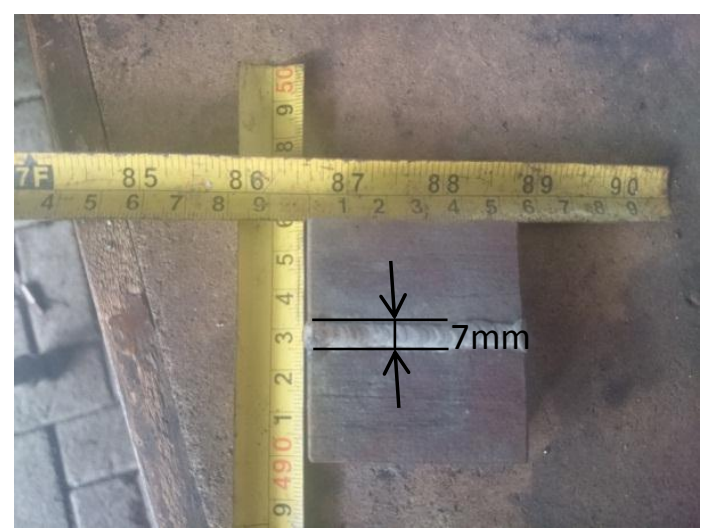

Gambar 4. Foto Hasil Pengelasan 120A.

Dari Gambar 4 merupakan hasil dari pengelasan GMAW menggunakan arus 120A. Pengelasan yang dilakukan mendapatkan lebar pengelasan $7 \mathrm{~mm}$.

\section{Pembahasan Hasil Pengelasan}

Dari gambar 2 didapat lebar hasil pengelasan $3 \mathrm{~mm}$, gambar 3 didapat lebar hasil pengelasan $5 \mathrm{~mm}$, dan gambar 4 didapat lebar hasil pengelasan $7 \mathrm{~mm}$. Maka dari ketiga hasil tersebut dapat disimpulkan bahwa semakin besar amper pengelasan maka semakin besar pula lebar hasil pengelasan. Hal ini dikarenakan nyala api pada pengelasan GMAW yang ditimbul akan semakin besar seiring semakin besarnya pula amper yang digunakan. Semakin besar api yang timbul dalam pengelasan ini maka akan semakin mudah pula filler meleleh, dan hasil pengelasan semakin sempurna.

\section{Hasil Uji Kekerasan}

Pengujian kekerasan ini bertujuan untuk mengetahui kekerasan material sebelum proses pengelasan dan sesudah proses pengelasan. Proses uji kekerasan ini bertujuan juga mengetahui apakah nanti ada perbedaan hasil kekerasan setelah spesimen dilakukan proses korosi. Proses uji kekerasan ini menggunakan mesin uji kekerasan yang terdapat dalam laboratorium tehnik UNWAHAS. Metode yang digunkan adalah menggunakan HRB. Dengan beban tekan $100 \mathrm{~kg}$. Adapun hasil yang didapat terlampir dalam tabel berikut : 


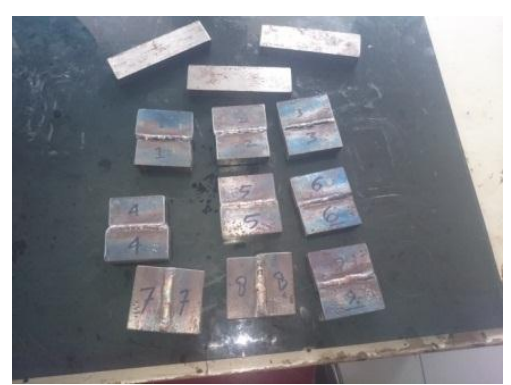

Gambar 5. Foto Material Sebelum Proses Korosi

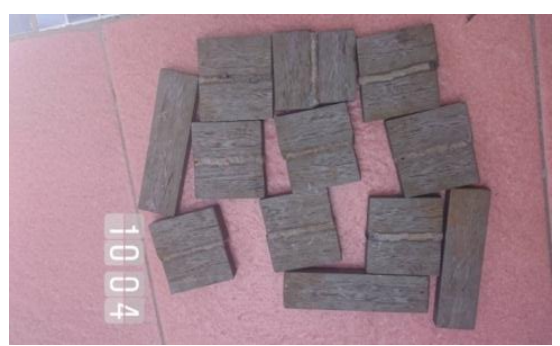

Gambar 6. Foto Material Pasca Proses Korosi

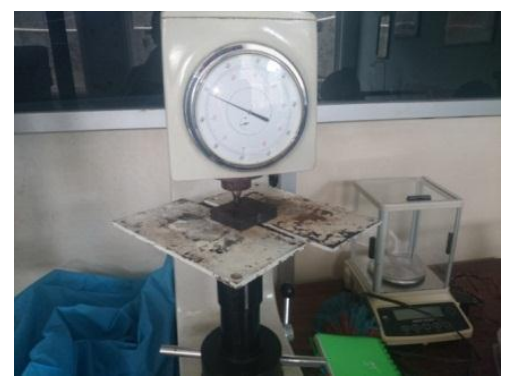

Gambar 7. Pengujian Kekerasan di Laboratorium UNWAHAS Semarang

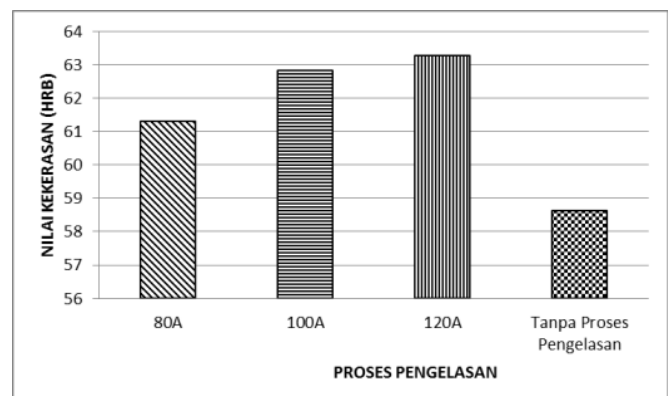

Gambar 8. Grafik Kekerasan Material Sebelum Proses Korosi

Dari Gambar 8 didapatkan hasil kekerasan material tertinggi terdapat pada proses welding 120A dengan hasil 63,1. Disusul dengan proses welding 100A, 80A, serta tanpa proses Welding. Grafik kekerasan material sebelum proses korosi dapat dilihat pada gambar 8 .

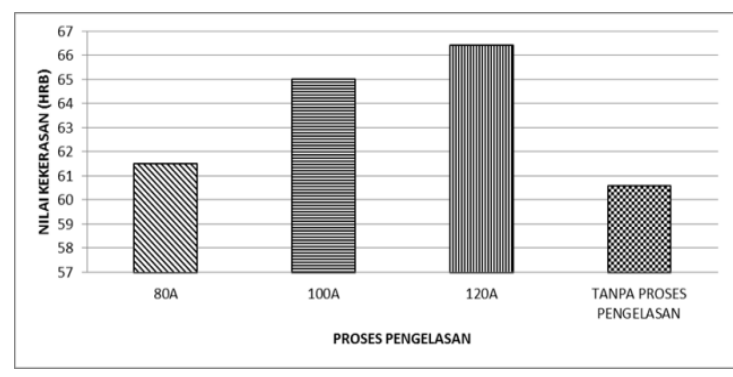

\section{Gambar 9. Grafik Kekerasan Material Setelah Proses Korosi}

Dari Gambar 9 didapatkan hasil kekerasan material tertinggi terdapat pada proses welding 120A dengan hasil 66,6. Disusul dengan proses welding 100A, 80A, serta tanpa proses Welding. Grafik kekerasan material setelah proses korosi dapat dilihat pada gambar 9 .

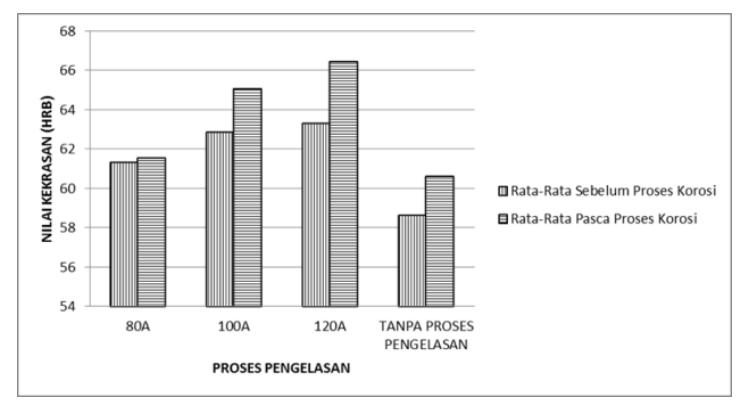

Gambar 10. Grafik Perbandingan Kekerasan Material Sebelum dan Setelah Proses Korosi

\section{Pembahasan Hasil Uji Kekerasan}

Dari Gambar 10 dapat di hasilkan bahwa semakin besar amper dalam pengelasan membuat material semakin keras, yaitu di dapat data 120 A dengan kekerasan 63,33, 62,8 dan 63,7. Dan kekerasan terendah didapat tanpa proses pengelesan yaitu 58,5, 60,1 dan 57,3. Setelah dilakukan uji korosi di dapat hasil yang sama juga, yaitu semakin besar amper yang digunakan, kekerasan material semakin besar pula walaupun sudah dilakukan uji korosi. Dengan data 120A memiliki kekerasan 64,4, 66,6, dan 683 serta kekerasan terendah didapat tanpa proses pengelasan dengan data $61,1,60,5$ dan 60,2. Data dapat dilihat pada Gambar 8 dan Gambar 9. Hal ini membuktikan bahwa semakin tinggi amper pengelasan akan berpengaruh terhapad kekerasan material. Hal ini dikarenakan nyala api yang lebih besar akan membuat temperatur pengelasan menjadi lebih tinggi dan menurut Fredikson (2008) mekanisme difusi adalah mengisi kekosongan 
atom pada daerah kumpulan atom, pengisian ini berjalan melaui batas butir dan koefisien difusi meningkat bila temperatur meningkat. Sehingga hal ini menyebabkan kekerasan material meningkat seiring dengan meningkatnya temperatur (Yogi, 2016).

\section{Hasil Uji Korosi}

Uji korosi merupakan pengujian dengan cara menimbang berat awal material sebelum proses korosi dan berat material sesudah proses korosi.

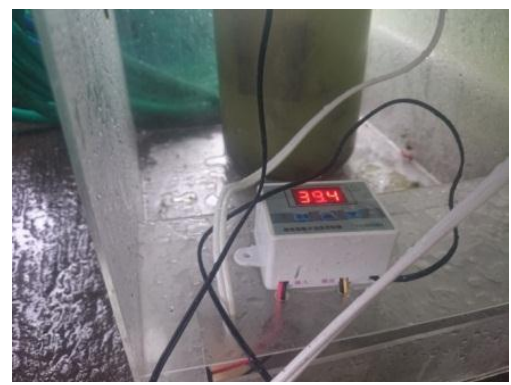

\section{Gambar 11. Foto Percobaan Korosi Pada Larutan HCl Dengan suhu $40^{\circ} \mathrm{C}$}

Hasil selisih berat material akan menyimpulkan hasil berapa besar laju korosi, dalam hal ini laju korosi yang diteliti adalah Baja ST60 yang dilakukan proses lasan, dengan variasi arus, yaitu 80A, 100A, dan 120A serta media korosif adalah larutan $\mathrm{HCl}$. Perobaan dilakukan selama 72 jam. Hasil Uji korosi dapat dilihat pada Gambar 12.

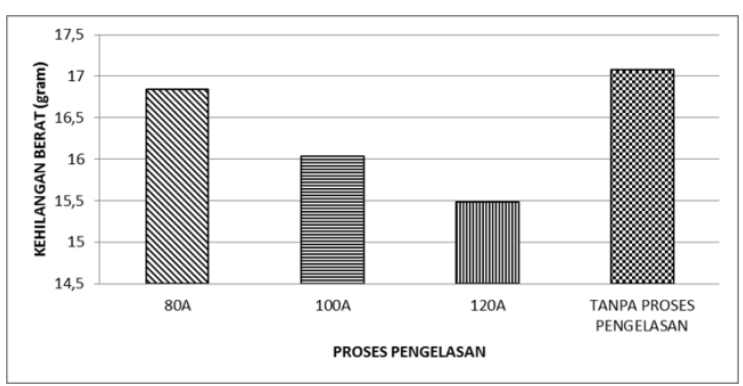

\section{Gambar 12. Grafik Selisih Laju Korosi Sebelum dan Pasca Proses Korosi}

Data tabel 12 didapat dengan cara pengukuran berat menggunakan timbangan digital, dengan akurasi ketepatan dua digit dibelakang koma. Proses dilakukan dilakukan selama 72 jam terhadap setiap spesimen. Dan suhu dijaga agar tetap konstan dengan menggunakan thermometer digital yang sekaligus dapat memutus atau menyambungkan arus kepada heater unutk menjaga agar suhu tetap $40^{\circ} \mathrm{C}$ dengan margin atas maupun bawah sebesar $2^{\circ}$.

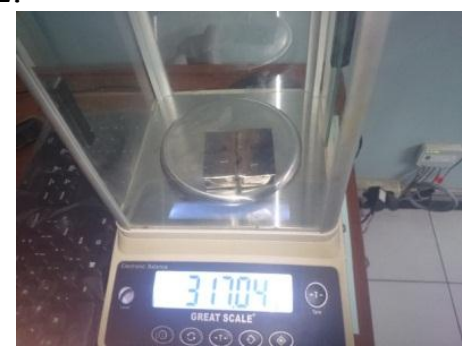

\section{Gambar 13. Penimbangan Material}

\section{Pembahasan Hasil Korosi}

Dari Hasil Tabel IV.4 dapat dihitung laju korosinya dengan menggunakan persamaan (Yogi, 2016).

Dimana : $\mathrm{CR}=\frac{K \cdot M}{\text { A.t. }} \frac{(m p y)}{(m m p y)}$.

Keterangan :

$\mathrm{CR}$ = Laju korosi

$\mathrm{K}=$ Konstanta $\left(3.45 \times 10^{6} \mathrm{mpy}\right)$

$\mathrm{M} \quad=$ Berat yang hilang (gram)

A $\quad=$ Luas sampel yang terendam $(\mathrm{cm} 2)$

$\mathrm{t} \quad=$ Waktu perendaman (jam)

$\rho \quad=$ Massa jenis logam $(\mathrm{g} / \mathrm{cm} 3)$

Tabel 1. Tabel Perhitungan Laju Korosi

\begin{tabular}{l|l}
\hline \multicolumn{1}{c|}{ Laju korosi 80A } & Laju korosi 100A \\
\hline CR & CR \\
$=\frac{3.45 \cdot 10^{6} \cdot 16,84}{76.72 .7,9}$ & $=\frac{3.45 \cdot 10^{6} \cdot 16,04}{27,5 \cdot 72 \cdot 7,9}$ \\
$\mathrm{CR}=\frac{58098000}{43228,8}$ & $\mathrm{CR}=\frac{55338000}{43228,8}$ \\
$13,43.10^{2} \mathrm{MPY}$ & $12,8 \cdot 10^{2} \mathrm{MPY}$ \\
\hline
\end{tabular}

\begin{tabular}{l|l}
\hline Laju korosi 120A & \multicolumn{1}{|c}{$\begin{array}{c}\text { Laju korosi } \\
\text { Tanpa } \\
\text { Pengelasan }\end{array}$} \\
\hline $\mathrm{CR}$ & $\mathrm{CR}$ \\
$=\frac{3.45 .10^{6} \cdot 15,48}{27,5.72 .7,9}$ & $=\frac{3.45 \cdot 10^{6} \cdot 17,07}{27,5 \cdot 72.7,9}$ \\
$\mathrm{CR}=\frac{53406000}{43228,8}$ & $\mathrm{CR}=\frac{58891500}{43228,8}$ \\
$12,35.10^{2} \mathrm{MPY}$ & $13,6.10^{2} \mathrm{MPY}$ \\
\hline
\end{tabular}




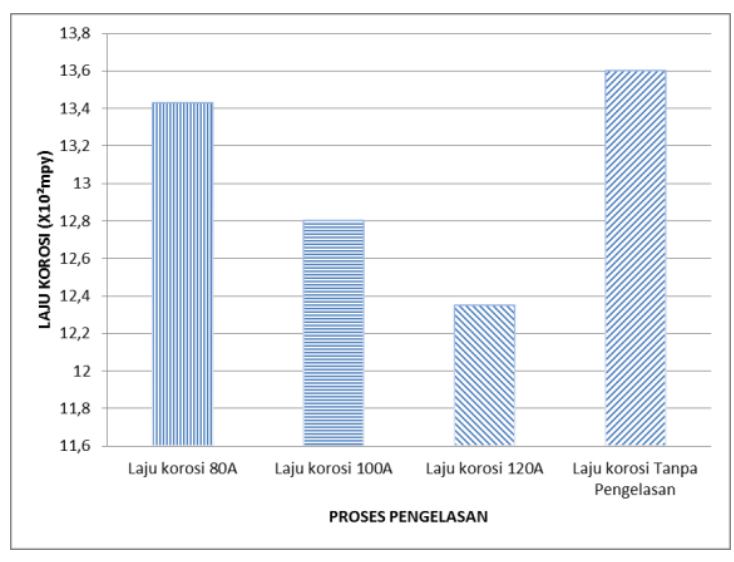

\section{Gambar 14. Grafik Laju Korosi}

Hasil dari pada tabel 1 dapat diketahui bahwa selisih terbesar atau pengkikisan material sehingga mengurangi berat material tertinggi pada material tanpa proses welding atau pengelasan, kemudian di susul dengan welding atau las-an $80 \mathrm{~A}, 100 \mathrm{~A}$, dan terakhir 120A. Dengan hasil selisih rata rata tanpa pengelasan 17,07 gram dan dengan las-an 120A didapat 15,48 gram.Serta laju korosi tertinggi pada proses tanpa pengelasan yaitu $13,6.10^{2} \mathrm{MPY}$, setelah itu turun $1,4 \%$ yaitu di pengelasan $80 \mathrm{~A}$ dengan hasil $13,43.10^{2} \mathrm{MPY}$, kemudian turun kembali $4,8 \%$ menjadi $12,8.10^{2} \mathrm{MPY}$ dan terakhir laju korosi terendah dengan pengelasan $120 \mathrm{~A}$, turun $9,3 \%$ menjadi $12,35.10^{2} \mathrm{MPY}$. Hal ini menjawab teori bahwa semakin keras suatu material, maka semakin lambat pula laju korosi pada material tersebut. Hal ini dikarenakan kandungan karbon yang berada pada meterial semakin banyak sehingga dapat mengurangi atau menghambat laju korosi (Putra, 2016).

\section{KESIMPULAN}

1. Dari peneliatian yang dilakukan ini pengaruh arus las GTAW dalam uji kekerasan adalah semakin besar arus las yang digunakan, akan membuat material menjadi keras pula. Dan mapad penelitian ini yang paling keras dengan menggunakan arus las 120A.

2. Dari penelitian yang dilakukan ini pengarus arus las GTAW dalam uji korosi adalah, semakin besar arus las yang digunakan, akan membuat laju korosi semakin rendah. Hal ini sesuai dengan terori bahwa semakin keras suatu material laju korosi akan semakin rendah.

\section{DAFTAR PUSTAKA}

Arya Aji Priatama, S. R. (2014). Pengaruh Temperatur Quench Terhadap Laju Korosi dan Struktur Mikro Hasil Pengelasan Baja Keylos 50.

Dwi Septianingsih, d. (2014). Pengaruh Variasi Konsentrasi Asam Klorida Terhadap Laju Korosi Baja Karbon Rendah Astm A139 Tanpa Dan Dengan Inhibitor Kalium Kromat 0,2\%, Jurusan Fisika FMPA Universitas Lampung.

Erizal Dwi Handoko, A. P. (2012). Analisa Korosi Erosi Pada Baja Karbon Sedang Akibat Aliran Air Laut, Jurusan Teknik Mesin, Universitas Diponegoro.

Fontana, M. (1987). Corrosion Engineering, 3 ed,. New York: Mc. Graw Hill Book Company.

Fontana, M. G. (1986). Corrosion Engineering. New York: Mc Graw-Hill.

Furqan, M. (2013, november 14). Corrosion Engineering. Dipetik mei 19, 2014, dari Himpunan Mahasiswa Mesin Unsyiah: http://m10mechanicalengineering.blogspot.c om/2013/11/macam-macam-bentuk-

korosi.html

Krisnayana, R. (2014, 9 1). Jenis-jenis Korosi. Dipetik April 6, 2017, dari Krisnayanarina.blogspot.in: krisnayanarina.blogspot.in/2014/09/jenisjenis-korosi.html?m=1

M Yogi Nasrul., H. S. (2016). Pengaruh Variasi Arus Las SMAW Terhadap Kekerasan Dan Kekuatan Tarik Sambungan Dissimilar Stainless steel 304 dan st 37, Tehnik Mesin, Universitas Negri Malang.

Pandu Damay Putra, H. P. (2016). Analisa Perbandingan Laju korosi di Lingkungan Laut dari Hasil Pengelasan GMAW pada Sambungan Alumunium Seri 5050 Karena Pengaruh Variasi Kecepatan Aliran Gas peindung, Fakultas Teknologi Kelautan, Institut Teknologi Sepuluh November(ITS).

Trethewy, K. \&. Chamberlain (1991). Korosi untuk Mahasiswa dan Rekayasawan. jakarta: PT. Gramedia Pustaka Utama. 